\section{MANAGEMENT OF HAEMORRHOIDS}

\section{Symptoms govern treatment}

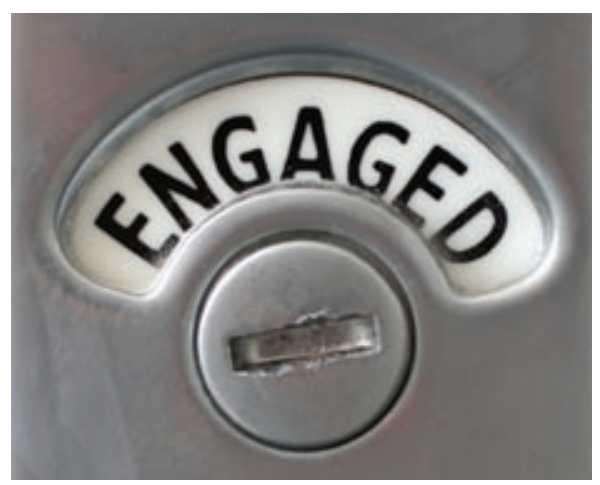

Acheson and Scholefield reviewed the management of haemorrhoids. ${ }^{1}$ At our centre, we have adopted an approach whereby symptoms govern the therapeutic decision.

For many patients, bleeding is the principal symptom, and we have used Doppler guided haemorrhoidal artery ligation (DGHAL) since 2004 in those whose condition has not improved after injection of oily phenol in the outpatient clinic. Over this time we have treated more than 400 patients. In 113 with long term follow-up, the rate of symptoms recurring was $19 \%$ at 30 months and the rate of complications low.

Although this technique has proved effective in the control of bleeding, it is not effective in the treatment of prolapsed haemorrhoids, with recurrence of prolapse occurring in $64 \%$ at 30 months. Many patients experience prolapse of their piles, which can lead to discharge of mucus, pruritus, and occasionally seepage of stool. Contrary to the cover of the BMJ, Acheson and Scholefield did not highlight the most recent advance in haemorrhoidal treatment.

Modification of the DGHAL transducer has allowed for the undertaking of DGHAL together with rectoanal repair (RAR). This technique was introduced at our unit in January 2007 to treat symptomatic prolapsed haemorrhoids. We have treated 92 patients with a symptomatic relief rate of $82 \%$ at three months. Although the inclusion of a RAR makes this a more painful procedure than DGHAL, patient satisfaction is high. More recently we have been undertaking DGHAL with or without RAR under conscious sedation, using midazolam and remifentanil. Altogether $48 \%$ of patients were entirely pain free during the procedure, with the remaining $52 \%$ having a median pain score of 3 out of
10. It is therefore possible to obtain pain free symptomatic relief of bleeding or prolapsed haemorrhoids in the day surgical setting. Simon B Middleton consultant colorectal surgeon simon.middleton@royalberkshire.nhs.uk Richard E Lovegrove specialist registrar in general surgery Howard Reece-Smith consultant general surgeon, Royal Berkshire Hospital, Reading RG15AN Competing interests: None declared.

1 Acheson AG, Scholefield JH. Management of haemorrhoids. BMJ 2008;336:380-3. (16 February.)

\section{LONG TERM OUTCOME OF STROKE}

\section{Stroke is a chronic disease with acute events}

Bruins et al and the accompanying editorial on stroke care make a compelling case for reviewing conventional policy approaches to stroke, which often show a dysequilibrium towards the (very important) front end of stroke, and a relative agnosia for (equally important) aftercare. ${ }^{1}$ Although it is clearly very important that all should have access to stroke unit care (and thrombolysis for those for whom it is indicated), most patients will still have residual disability after both of these interventions and will be more prone to further strokes than the rest of the population. Comprehensive national audits of stroke care show alarming levels of neglect in terms of chronic disease management and seem to indicate a collective nihilism about the potential for altering function and wellbeing after the early treatment of stroke, ${ }^{2}$ despite evidence of the effectiveness of continuing therapy and support at long intervals after stroke. ${ }^{3}$ We need to ensure that the potential for altering functional status and wellbeing is maximised at six months (and beyond). Highlighting the chronic disease aspect of stroke care may best serve this aspiration by promoting a timely focus on prevention, care, and support needs through patient education and empowerment, ${ }^{4}$ as well as the development of models of care which bring together primary and secondary care. ${ }^{5}$ This may require a reorientation of practice and training for stroke physicians, which do not currently emphasise the chronic course of the illness, or models of chronic disease management, which promote the role of the patient as partner.

Desmond O’Neill principal investigator des.oneill@amnch.ie Frances Horgan senior lecturer

Anne Hickey senior lecturer

Hannah McGee principal investigator, Irish National Audit of
Stroke Care, Royal College of Surgeons in Ireland, Dublin 2, Republic of Ireland

Competing interests: None declared.

1 Bruins Slot K, Berge E, Dorman P, Lewis S, Dennis M, Sandercock P, on behalf of the Oxfordshire Community Stroke Project, the International Stroke Trial (UK), and the Lothian Stroke Register Collaborative Groups. Impact of functional status at six months on long term survival in patients with ischaemic stroke: prospective cohort studies. BMJ 2008;336:376-9. (16 February.)

2 Horgan F, Hickey A, Murphy S, Wiley M, Conroy R, McGee H, et al. First Irish national audit of stroke care. Cerebrovasc Dis 2007;23(suppl 2):132.

3 Ouellette MM, LeBrasseur NK, Bean JF, Phillips E, Stein J, Frontera WR, et al. High-intensity resistance training improves muscle strength, self-reported function, and disability in long-term stroke survivors. Stroke 2004;35:1404-9.

4 Jones F. Strategies to enhance chronic disease selfmanagement: how can we apply this to stroke? Disabil Rehabil 2006;28:841-7.

5 Allen KR, Hazelett S, Jarjoura D, Wickstrom GC, Hua K, Weinhardt J, et al. Effectiveness of a postdischarge care management model for stroke and transient ischemic attack: a randomised trial. J Stroke Cerebrovasc Dis 2002;11:88-98.

\section{FOLLOW-UP AFTER BREAST CANCER}

\section{National randomised controlled trial is needed}

Dixon and Montgomery recommend that breast cancer follow-up be evidence based, flexible, and tailored to patients' needs. ${ }^{1}$ Unfortunately neither their proposal to provide only annual clinical review for two years nor the 2002 guideline from the National Institute for Health and Clinical Excellence, which recommends hospital based follow-up for no longer than three years for asymptomatic patients, is evidence based. A recent Cochrane review showed a wide range of recommendations for follow-up practice and identified the urgent need for a large randomised controlled trial to assess the optimum model of care. ${ }^{2} \mathrm{~A}$ key question in the debate is the rationale for follow-up. A recent survey of 256 breast surgeons and oncologists showed that follow-up was principally aimed at managing treatment related morbidity (93\%), alongside detecting new abnormalities (82\%), psychological morbidity (81\%), and recurrences (80\%). ${ }^{3}$ Dixon and Montgomery's optimism that (outside the guidance provided by the Quality and Outcomes Framework) timely intervention by primary care doctors will reduce anxiety or that assessment by note review should identify need for input at the time of mammography is not shared by colleagues who expressed concern about 


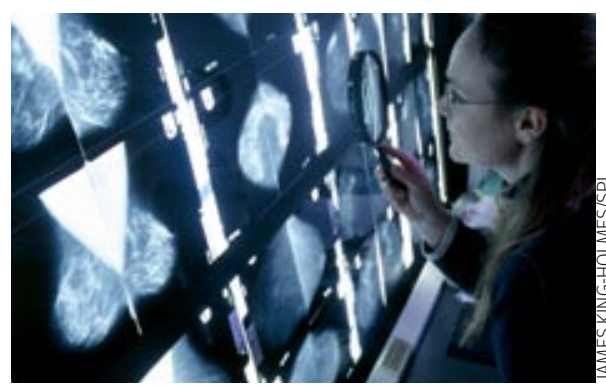

community support as a key factor in delaying discharge. ${ }^{3}$ If patients are to be given an alternative to hospital-based follow-up evidence is needed that alternative strategies work. Although there is some evidence from overseas that annual mammography is advantageous, the data are derived from health systems with strong private sector community support, which does not currently exist in the United Kingdom. ${ }^{4}$ Set against a background whereby two thirds of respondents were already undertaking annual mammography, median follow-up remains at five years (as per BASO guidance 2005), with many preferring hospital based follow-up for patients with a poor prognosis. ${ }^{3}$ Innovative models of alternative follow-up include radiographer led clinical review (Cardiff), nurse led telephone review (Manchester), patient led follow-up (Cambridge), and partnership with general practice (Oxford), which could meet our needs. The new national cancer plan recommends follow-up that is risk stratified but takes account of patients' need for choice, while tracking survivorship issues. A national multicentre randomised trial of hospital based specialist follow-up versus alternative follow-up, risk stratified for the Nottingham prognostic index, is urgently needed. Such a trial could capitalise on and promote those innovative models of care that most meet patients' needs while providing an effective means of auditing performance against NICE guidelines for adjuvant hormoneblocking therapy, bone health, and breast imaging. A proposed trial (iBREAST) requires adequate nursing and training resources to implement these alternative models of care. ${ }^{5}$

Peter K Donnelly consultant surgeon, South Devon Healthcare NHS Foundation Trust, Torquay TQ2 7AA peter.donnelly@nhs.net

Louise Hiller senior research fellow in medical statistics Janet A Dunn head of cancer trials,

Warwick Medical School Clinical Trials Unit, University of Warwick, Coventry CV47AL

Competing interests: None declared.

1 Dixon MJ, Montgomery D. Follow-up after breast cancer. BMJ 2008:336:107-8.

2 Rojas MP, Telaro E, Russo A et al. Follow-up strategies for women treated for early breast cancer. Cochrane Library, Issue 2. Chichester: Wiley, 2004.

3 Donnelly P, Hiller L, Bathers S, Bowden S, Coleman R. Questioning specialists' attitudes to breast cancer follow-up in primary care. Ann Oncol 2007;18:1467-76.
4 National Multidisciplinary Care Demonstration Project. Multidisciplinary care in Australia: a national demonstration project in breast cancer. Sydney: National Breast Cancer Centre, 2003.

5 Dunn J A, Donnelly P K, Barrett-Lee P, Beaver K, Cameron D, McCabe C, et al. iBREAST protocol submitted to HTA (2008).

\section{POSTGRADUATE PERFORMANCE}

\section{Study was flawed}

The news item by Mayor ${ }^{1}$ is based on a study by McManus et $\mathrm{al}^{2}$ that has serious flaws.

Firstly, the authors do not mention the limitations of using pre-admission academic qualifications as a measure of pre-admission academic ability. Since many medical students at all universities will have achieved the top grade in their $\mathrm{A}$ level or Scottish Highers examinations, this measure is subject to a particularly severe “ceiling effect." Nevertheless, pre-admission academic qualifications explained most of the variability (62\%) in the difference between the performances of each school's graduates, but this is potentially an underestimate because of the stated limitation.

Secondly, the outcome measures are results in postgraduate examinations, and the effect of postgraduate education is not measured in any meaningful way. This is important because it is well recognised that graduates from each school generally continue to work in close proximity to their school's area early in their career. The quality and quantity of postgraduate education will differ across the country. For example, from my own recent experience I am aware that there is a postgraduate programme of teaching aimed specifically at the Membership of the Royal College of Physicians (MRCP) part 1 exam at one of the highly performing institutions, but no such programme exists around one of the poorer performing ones. Also, a plethora of commercial and non-commercial courses are aimed at improving performance at these exams, mostly based in large cities in England or, to a lesser extent, central Scotland. Access to these may be more difficult for those graduates working around some of the poorer performing centres such as Belfast, Dundee, or Aberdeen, but this is not a reflection of poor undergraduate teaching at these universities. Roy L Soiza clinical lecturer, University of Aberdeen Medical School, Foresterhill, Aberdeen AB25 2ZD

r.l.soiza@abdn.ac.uk

Competing interests: RLS is an employee of the University of Aberdeen and a graduate of the University of Edinburgh.

1 Mayor S. Doctors from different schools vary in later postgraduate exams. BMJ 2008,336:347. (16 February.)

2 McManus IC, Elder AT, de Champlain A, Dacre JE, Mollon J, Cris L. Graduates of different UK medical schools show substantial differences in performance on MRCP(UK) part 1, part 2 and PACES examinations. BMCMed 2008;6:5.

\section{QUALITY FAILURES IN THE NHS \\ The windmills of your mind}

The notion that healthcare professionals do not care about quality is risible. Ham's illustration of the illusion of finance, finance, finance as the modus operandi of health care shows how badly the politicians who run and manage the NHS appreciate the issues. ${ }^{1}$ Successive "solutions" have been dominated by political meddling-for example, the National Patient Safety Agency. The educational role of the royal colleges in training doctors does not feature at all. Even more alarming is the fact that $10 \%$ of anything that can go wrong will go wrong, yet $10 \%$ of resources within the NHS or royal colleges are not given over to "patient safety." Does the teaching of a procedure include what to do if things go wrong, or, is it presumed that correct teaching will avert a catastrophe?

The notion that other industries are sorted out rather belies the complexity of healthcare delivery; so many specialties, so many patients, so many trusts all competing within a financially competitive market. If one looks at the beloved airline industry one will find that it is not incident reporting that is its hallmark of safety-it is the factoring out of human based practices and hierarchical apprentice systems, coupled with repetitive training. It is an industry norm that airline pilots are required to do six monthly safety and health assessments and cabin crew are given annual safety assessments. How many NHS staff are given safety assessments annually to ensure their competency? How many trust management systems and boards and executives receive annual training in patient safety?

When politicians return the NHS to the professionals then some headway may begin, but until then, like the windmills in your mind, there will be ever turning circles; some of us have been here before several times in our careers.

Jeffrey C Mcllwain consultant, clinical risk management, St Helens and Knowsley Teaching Hospitals NHS Trust, Merseyside L35 5DR

jeff.mcilwain@sthk.nhs.uk

Competing interests: None declared.

1 Ham C. Quality failures in the NHS. BMJ 2008;336:340-1. (16 February.)

\section{Memory is useful only if you consult it}

With reference to Ham's editorial, ${ }^{1} \mathrm{NHS}$ policy is often designed to benefit the interests of those in government and is consequently inconsistent, haphazard, and not holistic in its approach. The recent approach to hospital acquired infection sums this up, as a deep clean is preferred to tackling some of the root causes. The dangerous impact of targets is ignored as government 
ideology must be pursued at any cost, ${ }^{2}$ even this is to the detriment of patients. A useful memory would also be better built up if those in control actually listened to criticism coming from below, rather than ignoring and suppressing it.

There is no room for anyone else leading other than those who are commanding and controlling the Department of Health, hence the talk of leadership at a board and clinical level is empty. For a system to improve its quality via the use of memory, some scope must exist for local decisions to actually be made. Money is wasted on layers of bureaucracy that serve no purpose other than to take the blame when things go wrong. Currently the Department of Health is ordering a network of privately run walk-in centres to be opened in every primary care trust in the country by the end of 2008, even if some areas have no need for these expensive facilities and could better spend the money in other areas.

Over the past 10 years or so, a vast memory of information has been built up that shows that various reforms are not a cost effective way of spending taxpayers' money, but this memory is ignored, and reform goes on. So what is the point of a memory if the demented bandwagon is rolled on regardless?

Benjamin Dean senior house officer, Oxford djdeeno1979@yahoo.co.uk

Competing interests: None declared.

1 Ham C. Quality failures in the NHS. BMJ 2008;336:340-1. (16 February.)

2 Propper C, Burgess S, Gossage D. Competition and quality: evidence from the NHS internal market 1991-1999. www.bristol.ac.uk/cmpo/workingpapers/ wp77updated.pdf

\section{A prescription for amnesia}

I think that the (correct) gist of the rapid responses to Ham's editorial is that Ham's prescription is one for preposterous revisionism. ${ }^{1}$ He talks of "leadership," but he and his (political, health economist) ilk have succeeded beyond their wildest dreams in emasculating and proletarianising the medical profession. A brief perusal of the author's many publications offers a handy history of how the medical profession has been recently vilified, marginalised, and ultimately disempowered.

The Modernising Medical Careers catastrophe, General Medical Council and Postgraduate Medical Education and Training Board "reforms," and political control through targets and imposed contract settlements (in the teeth of sustained opposition) mean that doctors are now for the most part demoralised technicians or part time professionals.

The great future of medical leadership is all behind us, Professor Ham, and for health economists or pundits to suggest otherwise is disingenuous indeed.
Chris Luke consultant in emergency medicine, Cork University Hospital, Cork, Republic of Ireland cluke@muh.ie

Competing interests: $\mathrm{CL}$ is a former NHS consultant and director of postgraduate medical education.

1 Ham C. Quality failures in the NHS. BMJ 2008;336:340-1. (16 February.)

\section{We must forget all we know}

Has it occurred to Ham that the constant reorganisation of the command-led NHS has but one over-riding aim? ${ }^{1}$ To cause us to forget. What works is not the pertinent question. Rather, those who remember what does not work must be driven out.

L Sam Lewis general practitioner, Surgery, Newport, Pembrokeshire SA42 OTJ

sam@garthnewydd.freeserve.co.uk

Competing interests: None declared.

1 Ham C. Quality failures in the NHS. BMJ 2008;336:340-1. (16 February.)

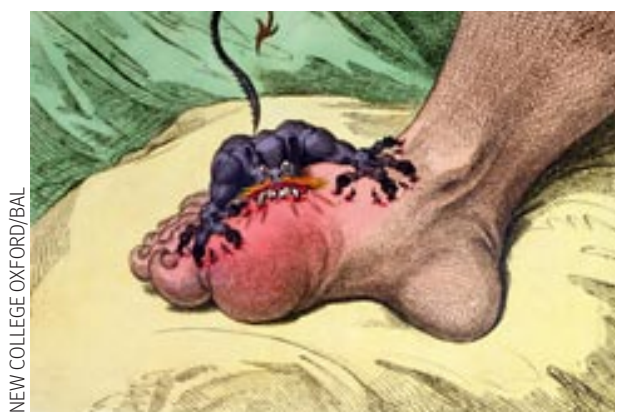

\section{MANAGEMENT OF RECURRENT GOUT Professional guidelines differ}

In his 10-minute consultation on the management of gout Fox ${ }^{1}$ provides a useful, concise summary.

We would like to draw attention to the British Society for Rheumatology (BSR) and British Health Professionals in Rheumatology (BHPR) guideline for the management of gout published in 2007. ${ }^{2}$ The guideline states that plasma urate should be maintained below $300 \mu \mathrm{mol} / \mathrm{l}$ to prevent recurrent attacks of gout as opposed to the $\leq 360 \mu \mathrm{mol} / \mathrm{l}$ quoted in the article by Fox. This is an important point since evidence suggests that at plasma urate concentrations above 300 $\mu \mathrm{mol} / \mathrm{l}$, recurrent attacks of gout may occur, and this is also observed in clinical practice. ${ }^{34}$ The guidelines also suggest that uric acid lowering treatment should be offered to patients after a second attack of gout or if a further attack occurs within a year, ${ }^{5}$ as opposed to the more than three attacks a year quoted in the article.

In addition to those with tophi and urate nephropathy, uric acid lowering therapy should also be offered to patients with renal insufficiency and to those who need to continue treatment with diuretics.
As clinicians, gout is one of the most rewarding diseases to manage, but many find it confusing and frustrating.

Susie C Earl specialist registrar in rheumatology searl@doctors.org.uk

Richard Hull consultant rheumatologis, Queen Alexandra Hospital, Portsmouth P06 3LY

Competing interests: None declared.

1 Fox R. Management of recurrent gout. $B M$ J 2008;336:329. (9 February.)

2 Jordan KM, Stewart Cameron J, Snaith M, Zhang W, Doherty $M$, Seck J, et al. British Society for Rheumatology and British Health Professionals in Rheumatology guideline for the management of gout. 2007. www.rheumatology.org. uk/guidelines/guidelines_other/goutguide

3 Roemjinders AC, Gorter KJ. Dutch general practitioners gout guidelines. Ned Tijd Genees 2002;146:309-13.

4 Shoji A, Yamanaka H, Kamatani N. A retrospective study of the relationship between serum urate level and recurrent attacks of gouty arthritis: evidence for reduction of recurrent gouty arthritis with antihyperuricemic therapy. Arthritis Rheum 2004;51:321-5.

5 Ferraz MB, O'Brien B. A cost effectiveness analysis of urate lowering drugs in nontophaceous recurrent gouty arthritis. J Rheumatol 1995;22:908-14.

\section{OTALGIA ARTICLE RIDES AGAIN}

\section{Specialists are critical too}

The 10-minute consultation on otalgia by Siddiq and Samra attracted criticism from general practitioners because of its lack of primary care focus. ${ }^{12}$ As hospital based doctors, we also wish to highlight problems with the article that could have ramifications if left uncorrected.

Trigeminal neuralgia is included as a cause of otalgia. In this condition, pain characteristically lancinates across the face, and, although there is often a trigger point anterior to the ear, ear pain is not typically seen. Otalgia is, however, a characteristic feature of glossopharyngeal neuralgia, which is not included in the list of causes. Glossopharyngeal neuralgia is associated with a high rate of underlying structural abnormality, including malignancies around or invading the carotid sheath, making it important to differentiate from trigeminal neuralgia, which has a benign cause in most cases. Additionally glossopharyngeal neuralgia can cause bradycardia and even asystole through facilitating cardioinhibitory reflexes. This cardioinhibition can prove fatal if not recognised but is treatable, often requiring a pacemaker. A patient presenting with a combination of otalgia and new onset collapses should be treated as a medical emergency. The other serious neurological consideration of otalgia is lateral sinus thrombosis, which is also omitted from the list of differential diagnoses. This condition may have other associated features such as generalised headache, seizure, or focal neurology and is commonly misdiagnosed.

Mark D Cossburn specialist registrar in neurology cossburnmd@hotmail.com

Owen R Pearson specialist registrar in neurology, University Hospital of Wales, Cardiff CF14 4XN 
Competing interests: None declared.

1 Siddiq MA, Samra MJ. Otalgia. BMJ 2008;336:276-7. (2 February.)

2 Extracts from responses. BMJ 2008;336:346. (16 February.)

\section{Teeth are rarely to blame}

Impacted teeth-teeth which have failed to fully erupt through the gums-are not in themselves symptomatic. ${ }^{1}$ They can develop an infection where the crown is partially covered by gum. This is called pericoronitis, and pain from this source would be referred to the ear only very rarely. More often pericoronitis causes pain and swelling in the mouth, on the gum, around the crown of the tooth.

If the impacted tooth becomes carious and the pulp becomes inflamed (pulpitis), this "toothache" is poorly localised and can be referred to the ear.

If the pulp of an impacted tooth dies, an abscess can form below the root of the tooth. The pain from a dental abscess is usually well localised to the tooth and the jaw around its roots.

Impacted teeth that are completely unerupted cause problems only if they develop associated pathology, such as a cyst, and this cyst becomes infected.

So we think listing impacted teeth in the list of causes of otalgia is a distraction. Pulpitis from any tooth is the most likely dental cause of pain referred to the ear.

Patrick Magennis consultant oral and maxillofacial surgeon Anne Begley consultant oral and maxillofacial surgeon,

University Hospital Aintree, Liverpool L97AL

maxfac@tiscali.co.uk

Competing interests: None declared.

1 Siddiq MA, Samra MJ. Otalgia. BMJ 2008;336:276-7. (2 February.)

\section{PRESUMED CONSENT AGAIN}

\section{Proactive opt-in already exists}

Boehm advocates a proactive approach in asking people whether they want to be an organ donor when they join a general practice. ${ }^{1}$ This question has been included on the form for registration with a general practitioner for many years. According to the UK Transplant website, ${ }^{2}$ people are also given the opportunity to opt in to organ donation when completing an application for a passport, driving licence, European Health Insurance Card, or Boots Advantage card. The system that Boehm proposes is therefore precisely the one that is in current use and that she says is not good enough. Simple it may be, but this approach has been tried and found wanting.

Michael Archer general practitioner, Grimston Medical Centre, King's Lynn, Norfolk PE32 1DW michaelarcher@tesco.net
Competing interests: None declared.

1 Boehm S. A bad choice. BMJ 2008;336:345. (16 February.)

2 UK Transplant. Routes to registration. www. uktransplant.org.uk/ukt/how_to_become_a_donor/ registration/routes_to_registration.jsp

\section{CONSULTANT MOTHERS}

\section{First courses now available}

I was interested to read Farrell's satirical view on the future of mothering, with prediction of the need for qualifications. ${ }^{1}$ You may be interested in the UK's first masters degree in parenting, being offered at De Montfort University, Leicester. It covers everything from "the theory and practice of parenting" to "the application of theory in parenting practice." I wonder whether this is the beginning of the future that Farrell predicts? Esther T Waterhouse consultant in palliative medicine, Leicester LE3 9QE

estherbryars@ntlworld.com

Competing interests: None declared.

1 Farrell L. The mother ship has come in. BMJ 2008;336:392. (16 February.)

\section{THE ERRORS IN OUR WAYS}

\section{Herpes of the Volvo}

Not only is handwriting subject to error through misinterpretation, ${ }^{1}$ but speech recognition software offers opportunities for more embarrassment. The incorrect words are automatically spelled correctly with woe to anyone who doesn't carefully proofread before sending.

"Orange Jews corrected his hypoglycemia" instead of "orange juice corrected his hypoglycaemia."

"She had herpes of the Volvo" instead of "herpes of the vulva." The machine is accurate, but the human is still human.

Howard J Homler solo practitioner, general internal medicine, Carmichael, CA 95608-6367, USA hhomler@ix.netcom.com

Competing interests: None declared.

1 Black ME. The errors in our ways. BMJ 2008;336:332. (9 February.)

\section{CLIMATE CHANGE}

\section{Wanted: a green NHS}

We welcome the BMJ's latest issue on climate change (26 January), which suggests some strategies for health professionals in response to global warming, including adaptation and surveillance and forecasting of health risks. " "Climate change: what can doctors do?" asks the BMJ's cover. We believe that doctors must do more than respond to the crisis as it unfolds. Health professionals at all levels must lead by example in their own practices.
The NHS in the United Kingdom emits 1 million tonnes of carbon every year and has an annual energy bill of around $f 400 \mathrm{~m}$ (€530; \$780). ${ }^{2}$ Although the UK government has committed $f 100 \mathrm{~m}$ to improving energy efficiency in the NHS, NHS carbon emissions rose by $11 \%$ between 2000 and 2005 as the number of buildings increased. ${ }^{3}$ Furlong noted in a recent $B B C$ programme that the NHS lags far behind other sectors. ${ }^{4}$ The Campaign for Greener Healthcare (www. greennhs.org) started in January with the mission of providing the NHS with active support in achieving sustainability in all areas of purchasing and provision. The campaign is working in partnership with government, the NHS, patients, and relevant industries.

We are convinced of the importance of a social, economic, and environmental approach to sustainability and also argue that fair and ethical trade is a crucial component of this in our connected world. ${ }^{5}$ As Roberts emphasises in the BMJ's issue, there are direct co-benefits to health in reducing carbon emissions, so by making the NHS more green we can clearly improve the health of the people we serve. We hope that healthcare professionals will support and be supported by our campaign.

Reward: a healthy future.

Rachel C Stancliffe director, Campaign for Greener Healthcare, Oxford OX27LG

rachel.stancliffe@soundshealthy.org

Mahmood Bhutta cofounder, Medical Fair and Ethical Trade Group, c/o International Department, BMA,

London WC1H 9JP

Competing interests: None declared.

1 Godlee F. Climate change: permission to act. Editor's choice. BMJ 2008;336. (26 January.)

2 Carbon Trust. NHS carbon management programme. www.carbontrust.co.uk/carbon/publicsector/nhs/

3 Department of Health. Sustainable development. Energy efficiency fund. www.dh.gov.uk/en/Policyandguidance/ Organisationpolicy/Estatesandfacilitiesmanagement/ Sustainabledevelopment/DH 074290

4 Furlong R. NHS: a long way from being green. http:// news.bbc.co.uk/go/pr/fr/-/1/hi/health/7109163.stm

5 Bhutta M. Fair trade for surgical instruments. BM 2006;333;297-9.

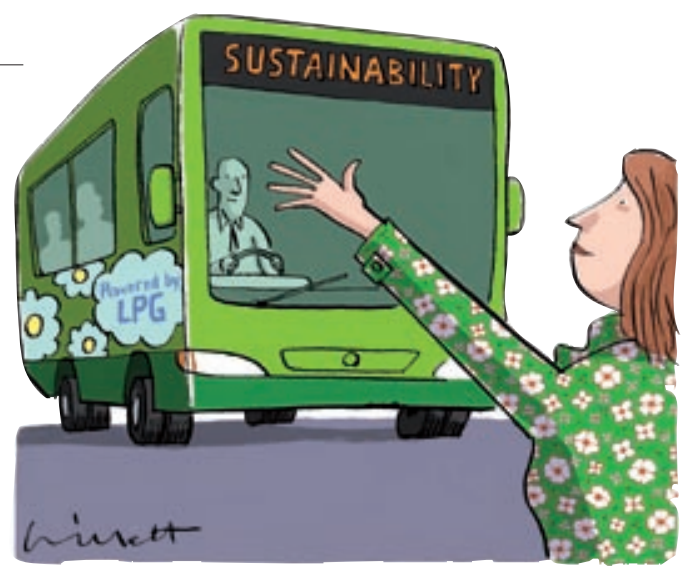

